\title{
Parejas del mismo sexo en Colombia: tres modelos para su reconocimiento jurídico y político
}

Este comentario, junto a los documentos que analiza, está disponible en www.anuariocdh.uchile.cl

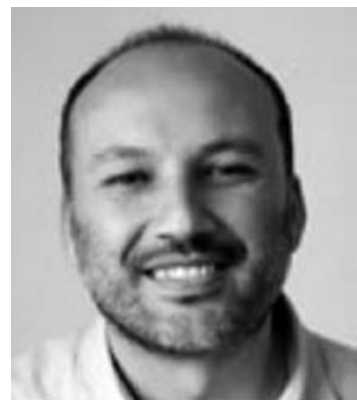

\section{Daniel Bonilla}

Profesor Asociado de la Universidad de los Andes, Bogotá, Colombia, y director del Grupo de Derecho de Interés Público de la misma universidad. Se graduó como abogado de la Universidad de los Andes y obtuvo su maestría y doctorado en derecho en la Universidad de Yale.

dbonilla@uniandes.edu.co

\section{RESUMEN}

Este artículo está dividido en tres secciones. En la primera se presenta la estructura básica de las decisiones de la Corte Constitucional colombiana que reconocieron jurídicamente a las parejas del mismo sexo y que le otorgaron un notable número de derechos. En la segunda, analítica y crítica, se justifican los argumentos que permiten afirmar que este conjunto de sentencias constituyen un paso importante hacia la eliminación de la discriminación que existe en Colombia en contra de la comunidad LGBT. En la tercera se exponen las características centrales de los modelos de la autonomía y la igualdad, que permiten justificar el reconocimiento jurídico de las parejas del mismo sexo, y se presentan sus principales debilidades. Del mismo modo, en esta sección, se exponen los elementos constitutivos del modelo de la dignidad y se presentan los argumentos que permiten afirmar que esta perspectiva normativa ofrece una más clara y completa explicación y fundamentación de la posición que promueve el reconocimiento jurídico de las parejas del mismo sexo.

En los últimos dos años, la Corte Constitucional colombiana se ha pronunciado en siete ocasiones sobre el estatus jurídico y los derechos de las parejas del mismo sexo. En este conjunto de sentencias, el tribunal se toma en serio el tema de los derechos de las minorías sexuales y ofrece un grupo de argumentos complejos para evaluar el estatus jurídico y político que deberían tener los miembros de la comunidad LGBT $^{1}$ en una democracia liberal como la colombiana. En este artículo, argumento en primera instancia, que con esta línea jurisprudencial la Corte Constitucional ha dado pasos fundamentales para eliminar la discriminación que existe en Colombia en contra de la comunidad LGBT$^{2}$. Por un lado, las sentencias C-075/2007, C-811/2007, T- 856/ 2007,

\footnotetext{
1 LGBT son las siglas que designan colectivamente a las personas lesbianas, gays, bisexuales y transgénero.

2 BONILLA, Daniel. Igualdad, orientación sexual y derecho de interés público: la historia de la sentencia C-075/07. En: Parejas del mismo sexo: el camino hacia la igualdad. Universidad de los Andes-Colombia Diversa. Bogotá, Colombia, 2008.
} 
C-336/2008, C-798 de 2008 y T-1241/2008, C-029/2009³ reconocen por primera vez en la historia del país la existencia jurídica de las parejas del mismo sexo y les otorga un conjunto importante de derechos y obligaciones constitucionales y legales. Estos derechos y obligaciones tocan temas tan variados como la dignidad humana, la igualdad, la salud, las pensiones y la nacionalidad de los miembros de las parejas del mismo sexo.

Por el otro, este conjunto de sentencias da un giro importante a la jurisprudencia de la Corte sobre los derechos de la comunidad LGBT. Con anterioridad a la expedición de la sentencia C-075/2007, la Corte había reconocido los derechos de los homosexuales en tanto individuos, pero se había negado de manera sistemática a reconocer la existencia jurídica de las parejas del mismo sexo y, por tanto, a reconocer que sus miembros eran titulares de derechos. Además, estas siete sentencias evidencian un giro importante, aunque no definitivo, en la interpretación que tiene la sociedad colombiana sobre la comunidad LGBT. El hecho de que estas sentencias fueran aprobadas por unanimidad o mayorías notables en una Corte que está constituida por varios magistrados comprometidos con posiciones políticas conservadoras refleja los cambios que se han venido dando en nuestro país en torno a la valoración social de las minorías sexuales que lo constituyen. Este giro se confirma por el hecho de que las sentencias fueran respaldadas o, por lo menos no cuestionadas, por amplios sectores de la población. Finalmente, estos fallos contribuyen a una mejor comprensión, evaluación y solución del problema que genera el no reconocimiento jurídico de las parejas del mismo sexo. Este grupo de sentencias, además de aproximarse a los dilemas teóricos y prácticos que genera la inexistencia jurídica de este tipo de parejas a través de los argumentos tradicionales de la autonomía y la igualdad, lo hace a través del argumento de la dignidad -mucho menos usado para acercarse a este tipo de problemas.

En segunda instancia, argumentaré que las razones que justifican este conjunto de sentencias responden a tres modelos distintos para comprender, evaluar y reconocer jurídicamente las parejas del mismo sexo: el modelo de la dignidad, el modelo de la igualdad y el modelo de la autonomía. Si bien los dos primeros modelos son complementarios entre sí, analizaré cómo éstos y el modelo de la autonomía son mutuamente excluyentes ${ }^{4}$. Igualmente, revisaré cómo la línea jurisprudencial de la Corte Constitucional colombiana que reconoció la existencia jurídica de las parejas del mismo sexo se fundamenta en modelos que están teórica y prácticamente en tensión.

Finalmente, analizaré cómo el modelo de la dignidad ofrece notables ventajas comparativas frente a los modelos alternativos porque (i) identifica el problema que está en juego de la manera más clara, precisa, sencilla y comprehensiva posible; (ii) explicita en forma precisa los obstáculos para solucionar el problema político y jurídico que implica el no reconocimiento jurídico de las parejas del mismo sexo; (iii) establece un criterio sólido para determinar la utilidad de los mecanismos que buscan neutralizarlo; y (iv) interpreta lúcidamente los modelos con los que compite y la perspectiva de moralidad política que sustenta nuestro sistema político-jurídico, esto es, el liberalismo.

3 La Corte Constitucional promulga dos tipos de sentencias: por un lado, las sentencias tipo " $\mathrm{C}^{\text {", }}$, en donde se hace un control abstracto de constitucionalidad, y, por ende, donde la argumentación se concentra en si existe coherencia o no entre una norma inferior y la Constitución. Este tipo de casos no vincula a ningún ciudadano concreto en el proceso. Por el otro, las sentencias tipo "T", donde la Corte revisa casos de tutela ya decididos por jueces inferiores en los que se alega que el Estado, o en algunos casos los particulares, violan por acción u omisión los derechos fundamentales de uno o más individuos.

4 Las consecuencias jurídicas y políticas sustanciales y procedimentales que generan estos modelos son distintas e incompatibles. BURT, Robert. Regulando la sexualidad: Libertad frente a Igualdad. En: Seminario en Latinoamérica de Teoría Constitucional y Política (SELA). 2009, p. 2, disponible en http://www.law.yale.edu/intellectuallife/sela2009. htm 
Para justificar estos argumentos dividiré este artículo en tres partes. En la primera presentaré la estructura básica de las decisiones de la Corte Constitucional colombiana que reconocieron jurídicamente a las parejas del mismo sexo y que le otorgaron un notable número de derechos. En la segunda, analítica y crítica, justificaré los argumentos que permiten afirmar que este conjunto de sentencias constituyen un paso importante hacia la eliminación de la discriminación que existe en Colombia en contra de la comunidad LGBT. En la tercera expondré las características centrales de los modelos de la autonomía y la igualdad y presentaré las que considero son sus principales debilidades. Del mismo modo, en esta sección, expondré los elementos constitutivos del modelo de la dignidad y presentaré los argumentos que permiten afirmar que esta perspectiva normativa ofrece una más clara y completa explicación y fundamentación de la posición que promueve el reconocimiento jurídico de las parejas del mismo sexo.

\section{El reconocimiento jurídico de las parejas del mismo sexo en Colombia}

La línea jurisprudencial articulada por la Corte Constitucional colombiana sobre parejas del mismo sexo puede dividirse en tres partes: reconocimiento, consolidación y expansión. En la primera, conformada por la sentencia C-075 de 2007, el tribunal constitucional por primera vez en la historia de Colombia reconoció la existencia jurídica de las parejas del mismo sexo. La Corte decidió que la Ley 54 de 1990, que regula todas las materias relacionadas con la unión marital de hecho, era aplicable tanto a las parejas heterosexuales como a las del mismo sexo. Señaló que el artículo 1 de la Ley 54, que definía la unión marital de hecho como aquella institución compuesta por un hombre y una mujer que cohabitan por al menos dos años, era constitucional únicamente si era aplicable también a las parejas homosexuales. Esta interpretación condicionada de su artículo 1, implicó que el resto de los preceptos que componen la Ley 54, que regulan los aspectos patrimoniales de la unión marital de hecho, fueran aplicables a todas las parejas, heterosexuales y homosexuales, que existen en el país.

La Corte señaló de manera inequívoca que su decisión se circunscribe únicamente a la Ley 54 de 1990. Este argumento resulta de particular importancia pues el artículo 1 de esta ley era el único que definía de manera clara y precisa la unión marital de hecho en el ordenamiento jurídico colombiano y constituía un referente ineludible para interpretar el amplio número de preceptos que precisan derechos y obligaciones para las personas que constituyen uniones maritales de hecho -normas que regulan materias tan distintas como la obtención de la ciudadanía, los seguros de automóviles y la obligación que tienen los padres y madres de proveer una cuota de alimentos para sus hijos. Si la Corte lo hubiera querido, con esta sola sentencia hubiera podido hacer una transformación global del sistema jurídico colombiano de manera que todas las normas que regulan la unión marital de hecho y sus consecuencias fueran aplicables tanto a las parejas heterosexuales como a las parejas del mismo sexo ${ }^{5}$. Si bien esta sentencia no tuvo este efecto, abrió el camino para que nuevas demandas que tuvieran como objetivo cuestionar la constitucionalidad de las normas jurídicas que hicieran referencia a la unión marital de hecho pero que siguieran siendo aplicadas únicamente a las parejas heterosexuales.

La segunda parte de esta línea jurisprudencial, constituida por las sentencias C-811/2007, C-336/2008, C-798/2008, T-856/ 2007 y T-1241/2008, confirma la regla jurisprudencial que indica que las parejas del mismo sexo pueden constituir uniones maritales de hecho, y amplió los derechos

\footnotetext{
5 La demanda que cuestionó la constitucionalidad de la Ley 54 de 1990 solicitó a la Corte que reconociera que la Ley 54 era un referente interpretativo de las otras normas que hacen referencia a la unión marital de hecho y, por tanto, le pidió al tribunal que generara un efecto dominó que hubiera transformado radicalmente el ordenamiento jurídico colombiano. La demanda fue presentada por el Grupo de Derecho de Interés Público de la Universidad de los Andes y la organización no gubernamental Colombia Diversa.
} 
y obligaciones que están en cabeza de sus miembros ${ }^{6}$. La primera sentencia reconoció que las normas que regulan la afiliación al sistema contributivo de salud de las parejas heterosexuales que conforman una unión marital de hecho son también aplicables a las parejas del mismo sexo. La segunda sentencia señaló que tanto los miembros de las parejas heterosexuales como las del mismo sexo pueden ser titulares de la pensión de sobrevivientes ${ }^{7}$. La tercera sentencia indica que tanto los miembros de las parejas del mismo sexo como las heterosexuales pueden ser titulares del derecho a recibir una cuota de alimentos por parte de su pareja una vez que se ha terminado la vida en común. Las últimas dos sentencias de revisión de tutela confirman el derecho que tienen los ciudadanos que hacen parte de parejas del mismo sexo a ser afiliados al sistema contributivo de seguridad social, por un lado, y a recibir la pensión de sobreviviente, por el otro. Estas sentencias concretan en dos casos de control concreto de constitucionalidad las reglas jurisprudenciales establecidas en los casos de control abstracto que fueron decididos anteriormente ${ }^{8}$.

La tercera etapa de esta línea jurisprudencial, que expande de manera radical el número de derechos y obligaciones que están en cabeza de los miembros de las parejas del mismo sexo, tiene como único, pero muy importante componente, la sentencia C-029/2009 ${ }^{9}$. Esta sentencia surge como consecuencia de una demanda que cuestionó la constitucionalidad de 26 normas jurídicas que diferenciaban injustificadamente entre las parejas del mismo sexo y las parejas heterosexuales ${ }^{10}$. Las normas que la Corte Constitucional declaró constitucionales de manera condicionada en esta sentencia pueden ser reunidas en los siguientes cinco grupos: penales, civiles y comerciales, seguridad social, políticas y aquellas relacionadas con el conflicto armado. La Corte señaló que este conjunto de normas jurídicas dirigidas a las parejas heterosexuales son constitucionales únicamente si se aplican también a las parejas del mismo sexo ${ }^{11}$.

El primer grupo de normas hace referencia a temas penales tan disímiles como el derecho a no declarar, denunciar o formular queja en contra de los compañeros permanentes en cualquier materia disciplinaria, penal y penal militar ${ }^{12}$; el beneficio de prescindir de la sanción penal no privativa de la libertad cuando el sujeto pasivo del delito es el compañero permanente ${ }^{13}$; y la agravación punitiva para el sujeto activo de una conducta delictiva de la cual su compañero permanente es la víctima ${ }^{14}$.

6 Grupo de Derecho de Interés Público de la Universidad de los Andes, Informe para el $18^{\circ}$ Congreso Internacional de Derecho Comparado, Washington D.C., 2010.

7 Esto es, que cuando un integrante de la pareja que recibe una pensión muere, el que le sobrevive puede sustituirlo como beneficiario de este derecho.

8 En la sentencia T-1241/2008, la Corte Constitucional ordenó a la Caja de Retiro de las Fuerzas Armadas reformar todos sus procedimientos de manera que los miembros de las parejas del mismo sexo puedan hacer uso de su derecho a la sustitución pensional. Sin embargo, no concedió la tutela en tanto que el ciudadano que presentó la tutela no adjuntó pruebas suficientes de su calidad de compañero permanente de la persona que murió, y a quien la Caja de Retiro de las fuerzas armadas estaba obligada a pagarle una pensión.

9 Grupo de Derecho de Interés Público de la Universidad de los Andes, Informe para el $18^{\circ}$ Congreso Internacional de Derecho Comparado, Washington D.C., 2010.

10 Esta demanda fue presentada por las organizaciones no gubernamentales Colombia Diversa y Dejusticia, así como por el Grupo de Derecho de Interés Público de la Universidad de los Andes.

11 La Corte, sin embargo, se inhibió de decidir sobre la constitucionalidad de las normas que incluyen los conceptos de familia, familiar o grupo familiar.

12 Artículos 8-b, 282, 303, 385, Ley 906 de 2004; artículos 222, 431, 495, Ley 522 de 1999; y artículo 71, Ley 734 de 2002.

13 Artículo 34, Ley 599 de 2000 y artículo 18, Ley 1153 de 2007.

14 Artículos 104, 170, 179, 188-B, 245, Ley 599 de 2000. La sentencia se refiere también a los siguientes temas penales: aplicación de la sanción prevista para quien cometa el delito de inasistencia alimentaria (artículo 233, Ley 599 de 2000); aplicación de la sanción para el sujeto activo del delito de malversación y dilapidación de bienes familiares cuando se es tutor o curador de los bienes del compañero permanente (artículo 457, Código Civil y artículo 236, Ley 599 de 
El segundo conjunto de normas, civiles y comerciales, giran en torno a temas tan diversos como la constitución del patrimonio inembargable de familia ${ }^{15}$, la afectación de la vivienda familiar con el fin de proteger los bienes y vivienda de las parejas ${ }^{16}$ y la obligación de pagar una cuota de alimentos al compañero permanente una vez se haya terminado la vida en común ${ }^{17}$.

El tercer grupo de normas, reunidas bajo la categoría "seguridad social", se refiere a la posibilidad de que los miembros de las parejas del mismo sexo obtengan los beneficios que en materia de salud y pensiones reciben los miembros de las parejas heterosexuales que pertenecen a la fuerza pública ${ }^{18}$; y a que las personas que hacen parte de parejas del mismo sexo obtengan los subsidios familiares que reciben los miembros de las parejas heterosexuales, por ejemplo, los de vivienda y educación ${ }^{19}$.

El cuarto conjunto de normas regula las materias relacionadas con el régimen de inhabilidades e incompatibilidades y las restricciones al acceso y ejercicio de la función pública y la contratación estatal $^{20}$, así como la aplicación de los requisitos para adquirir la nacionalidad por adopción ${ }^{21}$. Finalmente, el quinto grupo de normas hace referencia a cuestiones tan importantes como el derecho que tienen los compañeros permanentes de las personas que han sido sujetos pasivos de delitos atroces a que se presuman como víctimas y que, por tanto, tengan derecho a la verdad, justicia y reparación ${ }^{22}$.

La línea jurisprudencial articulada por la Corte Constitucional en estas siete sentencias es consistente. Todas las sentencias parten de la premisa que indica que los miembros de las parejas del mismo sexo son sujetos de derecho y, por ende, titulares de un conjunto importante de obligaciones y derechos particulares. Del mismo modo, los siete fallos se fundan en los mismos tres pilares jurídicos que fueron fijados por la sentencia C-075/2007: dignidad, libre desarrollo de la personalidad e igualdad ${ }^{23}$.

Estas tres categorías jurídicas son definidas por la Corte Constitucional apelando a interpretaciones estándares del cuerpo teórico del liberalismo. Cada una de éstas, a su vez, se constituye en el eje de uno de los tres modelos que justifican el reconocimiento jurídico de las parejas del mismo sexo

2000); aplicación del castigo para quien cometa los delitos de violencia intrafamiliar (artículo 229, Ley 599 de 2000 y artículo 2, Ley 294 de 1996) y amenaza contra testigo o su compañero permanente (artículo 454-A, Ley 599 de 2000).

15 Artículo 4, Ley 70 de 1931.

16 Artículos 1 y 12, Ley 258 de 1996.

17 Artículo 11, Código Civil.

18 Artículo 3, Ley 923 de 2004; artículo 24, Decreto 1795 de 2000.

19 Artículos 1, 27, Ley 21 de 1982; artículo 7, Ley 3 de 1991.

20 Artículo 14, Ley 190 de 1995; artículo 1, Ley 1148 de 2007; artículo 8, Ley 80 de 1993; artículos 40, 84, Ley 734 de 2002; artículos 283, 286, Ley 5 de 1992.

21 Artículo 5, Ley 43 de 1993.

22 Artículos 5, 7, 15, 47, 48, 58, Ley 975 de 2005; artículo 11, Ley 589 de 2000; artículos 14, 15, Ley 971 de 2005; artículo 2, Ley 387 de 1997. La sentencia también hace referencia al derecho que tienen los compañeros permanentes de las víctimas de los delitos de desaparición forzada, secuestro y toma de rehenes a ser beneficiarios de las medidas de protección civil que el gobierno tiene la obligación de proveer (artículo 10, Ley 589 de 2000; artículos 2, 26, Ley 986 de 2005); $y$ el derecho a que las parejas del mismo sexo tengan la posibilidad de hacer uso de los mecanismos que permiten el acceso a la tierra en áreas rurales a los miembros de las parejas heterosexuales (artículos 61, 62, 80, 159, 161, 172, Ley 1152 de 2007).

23 A este respecto señala la Corte en la sentencia C-075 de 2007, "[e]n ese escenario, para la Corte, la ausencia de protección en el ámbito patrimonial para la pareja homosexual resulta lesiva de la dignidad de la persona humana, es contraria al derecho al libre desarrollo de la personalidad y comporta una forma de discriminación proscrita por la Constitución". 
que analizaré en la tercera sección de este escrito (libre desarrollo de la personalidad/modelo de la autonomía; igualdad/modelo de la igualdad y dignidad/modelo de la dignidad).

Para la Corte la dignidad es a la vez un atributo que tienen todos los seres humanos y un principio que funda el Estado Social de Derecho ${ }^{24}$. La Corte argumenta que la dignidad es una cualidad que tienen todas las personas por el solo hecho de pertenecer a la especie humana; una consecuencia de la capacidad que tienen todos los individuos de escoger sus proyectos morales y de justicia haciendo uso de la razón. Es decir, la dignidad es un atributo que surge como consecuencia de la autonomía y la racionalidad que son propias de la naturaleza humana. Es la cualidad que garantiza la igualdad básica de todos los seres humanos. En tanto que somos dignos, argumenta la Corte, todos somos iguales.

Para la Corte, este atributo es a su vez un principio constitucional que constituye la premisa de la cual se deducen los derechos fundamentales de las personas. Estos derechos son los instrumentos que permiten defender la dignidad humana de las intervenciones indebidas del Estado y de los particulares. Los derechos fundamentales son las herramientas que permiten que la naturaleza humana sea protegida y tenga la posibilidad de florecer. Consecuentemente, para la Corte, el principio de dignidad tiene una dimensión negativa y una positiva ${ }^{25}$. Por un lado, el Estado tiene el deber de abstenerse de adelantar cualquier tipo de acción que vulnere la autonomía de los seres humanos ${ }^{26}$; por el otro, tiene el deber de garantizar las condiciones materiales mínimas que permiten que la autonomía pueda ejercerse ${ }^{27}$. Para la Corte, la autonomía no se puede poner en práctica si los individuos no pueden satisfacer sus necesidades vitales básicas, por ejemplo, las relacionadas con la salud o el número de calorías necesarias para sobrevivir.

Para la Corte Constitucional, el libre desarrollo de la personalidad es un derecho que protege de manera amplia la autonomía de los individuos. La Corte lo entiende, fundamentalmente, como el derecho a "ser dejado solo", es decir, el derecho a que el Estado y otros individuos se abstengan de cruzar la frontera que protege el espacio en donde las personas articulan, transforman e

24 La Corte señala a este respecto, "Esta Corporación ha expresado que la dignidad humana es un valor superior y un principio fundante del Estado Social de Derecho, conforme al cual todas las personas deben recibir un trato acorde con su naturaleza humana. Ha señalado la Corte que "... dentro del sistema constitucional colombiano, el principio de dignidad constituye el centro axiológico a partir del cual se derivan las obligaciones de protección, respeto y promoción de los derechos constitucionales y el aseguramiento del cumplimiento de los deberes constitucionales, bajo la égida del orden justo". Para la Corte, "[p]or dignidad se entiende la supremacía que ostenta la persona como atributo inherente a su ser racional, cuya valoración y reconocimiento no puede estimarse como la causa o el efecto de alguien o de algo (es decir, como objeto), sino como un fin superior que subyace en sí mismo" (Notas al pie eliminadas).

25 "De manera general, de acuerdo con la jurisprudencia constitucional, la dignidad humana, como principio fundante del Estado, es el presupuesto esencial de la consagración y efectividad del sistema de derechos y garantías contemplado en la Constitución y tiene, por consiguiente, valor absoluto no susceptible de ser limitado bajo ninguna circunstancia. De este modo, si bien la Constitución impone como límite al libre desarrollo de la personalidad los derechos de los demás y el orden jurídico, tal límite no puede llevarse al extremo de instrumentalizar a la persona para el logro del interés general en condiciones que afecten su dignidad. Finalmente cabe señalar que, de acuerdo con la jurisprudencia, el principio de dignidad humana comporta un mandato constitucional que determina no sólo un deber negativo de no intromisión sino también un deber positivo de protección y mantenimiento de condiciones de vida digna" (Notas al pie eliminadas).

26 Esto es lo que la Corte ha Ilamado de manera diciente el derecho que tienen los individuos a "vivir como se quiera" y a "vivir sin humillaciones". Ver, por ejemplo, Corte Constitucional, Sentencia T-881 de 2002, MP: Eduardo Montealegre Lynett; Corte Constitucional, Sentencia C-221 de 1994, MP: Carlos Gaviria Díaz; Corte Constitucional, Sentencia T-881 de 2002, MP: Eduardo Montealegre Lynett; Corte Constitucional, Sentencia C-521 de 1998, MP: Antonio Barrera Carbonell. De igual forma, ver La Demanda, en Parejas del mismo sexo: el camino hacia la igualdad -Sentencia C-075/07, Colombia Diversa- Universidad de los Andes, 2008, pp. 106-110.

27 Esto es lo que la Corte ha Ilamado la dimensión material del principio de dignidad. Esta dimensión se concreta en el derecho constitucional de creación jurisprudencial al mínimo vital. Ver, por ejemplo, Sentencias SU-225 de 1998 , SU-995 de 1999, C-778 de 2003, T-326 de 1992 y T-533 de 2002. 
intentan materializar su proyecto de buen vivir. De esta forma, el libre desarrollo de la personalidad concreta, promueve y protege el principio de dignidad humana ${ }^{28}$. Ahora bien, para el tribunal constitucional, siguiendo con la interpretación estándar que tiene el liberalismo de la autonomía individual, el libre desarrollo de la personalidad se entiende como un derecho relativo. El orden jurídico y los derechos de los demás se constituyen en límites legítimos para la autonomía de los sujetos.

Por último, la Corte entiende la igualdad, apelando nuevamente a una interpretación estándar del canon liberal, como el derecho a que casos análogos sean tratados de manera análoga y que casos disímiles deban ser tratados de manera disímil. Para la Corte, en consecuencia, este derecho implica que los sujetos no pueden ser discriminados por parte del Estado y que cualquier trato diferenciado de la administración debe ser adecuadamente justificado -en particular, cuando quienes son tratados de manera diferente son grupos de individuos que han sido históricamente discriminados en la comunidad política.

Esta línea argumentativa es seguida fielmente por las otras seis sentencias que constituyen la línea jurisprudencial sobre parejas del mismo sexo (C-811/200729, T- 856/2007 ${ }^{30}$, y C-336/2008 31 , T-1241/2008 32 , C- 798/2008 33 y C-029/200934).

28 " [...] [E]sta Corte ha entendido que el derecho al libre desarrollo de la personalidad consagra una protección general de la capacidad que la Constitución reconoce a las personas para autodeterminarse, esto es, a darse sus propias normas y desarrollar planes propios de vida, siempre y cuando no se afecten derechos de terceros o el orden jurídico" (Nota al pie eliminada).

29 Al respecto dice la Corte en la sentencia C-811/2007, "Para realizar el estudio de la disposición acusada, la Corte debe considerar los elementos doctrinarios establecidos en la Sentencia C-075 de 2007, pues ésta se constituye en el marco conceptual que determina el alcance actual de los derechos de las parejas del mismo sexo"..."En efecto, acogiendo los criterios doctrinales esbozados por la Corte en la Sentencia C-075 de 2007, que marcan la perspectiva actual en el tratamiento jurídico del tema, el impedimento que tiene la pareja del mismo sexo de vincularse al sistema de Seguridad Social en Salud por el régimen contributivo constituye una vulneración de su derecho a la dignidad humana, el libre desarrollo de la personalidad -en la concepción de la autodeterminación sexual-, así como una transgresión de la proscripción de discriminación por razón de la orientación sexual".

30 Ver secciones 4 y 5 de la sentencia T-856/2007 en donde se citan las sentencias C-075 de 2007 y C-811 de 2007 como precedentes obligatorios para decidir el caso de tutela que se revisa.

31 La Corte señala a este respecto en la sentencia C-336/2008, "En el presente caso, la aplicación de las expresiones demandadas ha permitido dar a las parejas homosexuales un tratamiento distinto al que se otorga a las parejas heterosexuales en cuanto éstas son beneficiaria (sic) de la pensión de sobrevivientes y aquellas no, trato distinto que resulta discriminatorio respecto de las parejas homosexuales, las cuales, aun cuando no están excluidas de manera expresa de los beneficios de la pensión de sobrevivientes, sí resultan de hecho exceptuadas del sistema de seguridad social, pues la falta de claridad del legislador ha conducido a implementar una situación contraria a los valores del Estado Social de Derecho, a los principios de reconocimiento y respeto por la dignidad de la persona humana, y a las normas que desde la Constitución amparan el libre desarrollo de la personalidad y su extensión: la libertad de opción sexual". Ver también el numeral 5 de la sentencia en donde se recoge la doctrina expuesta en la sentencia C-075 de 2007.

32 Ver secciones 4.2 y 4.3 de la sentencia T-1241/2008 en donde se citan tanto la sentencia C-336 de 2008 como la sentencia C-075 de 2007 como fundamento de la decisión que la Corte Constitucional toma en esta tutela.

33 La Corte señala en la sentencia C-798/2008, “... el régimen patrimonial de las uniones maritales de hecho -aquellas dentro de las cuales rige el deber de alimentos- se encuentra recogido en la Ley 54 de 1990, tal como fue modificada por la Ley 979 de 2005. Como se sabe, la sentencia C-075 de 2007, la Corte declaró exequible la Ley 54 de 1990 ...en el entendido que el régimen de protección de los derechos patrimoniales de los compañeros permanentes que forman una unión marital de hecho, se aplica también a las parejas homosexuales...La interpretación sistemática de las disposiciones mencionadas y las decisiones judiciales citadas, no arroja ninguna duda sobre la existencia de la obligación alimentaria entre compañeros permanentes, con independencia de su orientación sexual...". Ver también apartado 13 de esta misma sentencia.

34 "Sin embargo, es preciso tener en cuenta que, de acuerdo con la jurisprudencia constitucional, la pareja, como proyecto de vida en común, que tiene vocación de permanencia e implica asistencia recíproca y solidaridad entre sus integrantes, goza de protección constitucional, independientemente de si se trata de parejas heterosexuales o parejas homosexuales, y que, en ese contexto, la diferencia de trato para parejas que se encuentren en situaciones asimilables puede plantear problemas de igualdad y que, del mismo modo, la ausencia de previsión legal para las parejas del mismo sexo en 
Ahora bien, la Corte establece una conexión estrecha entre las normas demandadas y las acciones de la administración cuestionadas en los siete casos relacionados con las parejas del mismo sexo, por un lado, y la violación tanto de los derechos a la igualdad y el libre desarrollo de la personalidad como del principio de dignidad humana, por el otro. Señala que las parejas del mismo sexo y las parejas heterosexuales son iguales en todas las materias definidas y reguladas por la figura de la unión marital de hecho. Para la Corte no hay diferencias jurídicamente relevantes para distinguir a las parejas del mismo sexo y a las heterosexuales en estas materias. Las dos son formas de asociación que permiten que los individuos compartan su vida sexual, afectiva y patrimonial. Por tanto, cualquier interpretación de estas normas que excluya de su ámbito de aplicación a las parejas del mismo sexo es inconstitucional en tanto que diferencia injustificadamente entre dos formas de asociación a las que pueden legítimamente apelar los ciudadanos para materializar sus proyectos de buen vivir.

A su vez, estas normas restringen indebidamente la autonomía de los individuos ${ }^{35}$. El no reconocimiento jurídico de las parejas del mismo sexo desincentiva y hace menos viables los proyectos de buen vivir que involucran la vida en común de individuos con orientaciones sexuales no tradicionales. Finalmente, este conjunto de normas viola la dignidad humana, esto es, la capacidad que tienen los seres humanos para escoger e intentar materializar a través de la razón sus proyectos de buen vivir ${ }^{36}$. Para la Corte Constitucional, el no reconocimiento jurídico de las parejas del mismo sexo niega la pertenencia plena al género humano de los miembros de este tipo de parejas. Este conjunto de normas y acciones estatales no permiten que las personas "vivan como quieran", "vivan sin humillaciones" y tengan acceso a unas condiciones materiales mínimas para sobrevivir"

\section{La importancia de las sentencias}

El conjunto de siete sentencias en donde la Corte Constitucional colombiana reconoce la existencia jurídica de las parejas del mismo sexo y les concede a sus miembros un conjunto amplio de derechos es relevante por las siguientes cuatro razones. En primera instancia, con estas decisiones la Corte

relación con ventajas o beneficios que resultan aplicables a las parejas heterosexuales, puede dar lugar a un déficit de protección contrario la Constitución, en la medida en que desconoce un imperativo superior conforme al cual, en determinadas circunstancias, el ordenamiento jurídico debe contemplar un mínimo de protección para ciertos sujetos, mínimo sin el cual pueden verse comprometidos principios y derechos superiores, como la dignidad de la persona, el libre desarrollo de la personalidad o la solidaridad". Sentencia C-029 de 2009.

35 De manera paradigmática indica la Corte en la sentencia C-075 de 2007, “Dicho de otra manera, la decisión legislativa de no incluir a las parejas homosexuales en el régimen patrimonial previsto para las uniones maritales de hecho, comporta una restricción injustificada de la autonomía de los integrantes de tales parejas y puede tener efectos lesivos, no sólo en cuanto obstaculiza la realización de su proyecto de vida común, sino porque no ofrece una respuesta adecuada para las situaciones de conflicto que se pueden presentar cuando por cualquier causa cese la cohabitación".

36 Paradigmáticamente señala la Corte en la sentencia C-075 de 2007, "En el ámbito del problema que ahora debe resolver la Corte, resulta claro que la falta de reconocimiento jurídico de la realidad conformada por las parejas homosexuales es un atentado contra la dignidad de sus integrantes porque lesiona su autonomía y capacidad de autodeterminación al impedir que su decisión de conformar un proyecto de vida en común produzca efectos jurídico patrimoniales, lo cual significa que, dado un régimen imperativo del derecho civil, quedan en una situación de desprotección que no están en capacidad de afrontar. No hay razón que justifique someter a las parejas homosexuales a un régimen que resulta incompatible con una opción vital a la que han accedido en ejercicio de su derecho al libre desarrollo de la personalidad, ni resulta de recibo que la decisión legislativa de establecer un régimen para regular la situación patrimonial entre compañeros permanentes, sea indiferente ante los eventos de desprotección a los que puede dar lugar tratándose de parejas homosexuales".

37 La Corte hace referencia al caso de los miembros de parejas del mismo sexo de bajos recursos económicos que sobreviven a su pareja y no tienen derecho a la sustitución pensional o a aquellos que una vez se separan de su pareja o ésta muere no tienen derecho al patrimonio que construyeron conjuntamente en tanto que éste estaba a nombre únicamente de la persona que murió o de quien se separó. 
ataca de manera frontal un problema que debilita seriamente al ordenamiento jurídico-político colombiano: la existencia injustificada de dos tipos de ciudadanía. De un lado, los ciudadanos heterosexuales, que son definidos por el sistema jurídico como ciudadanos de primera categoría; del otro, los ciudadanos con orientaciones sexuales alternativas, que son tratados por este mismo sistema como ciudadanos de segunda categoría.

Los fallos de la Corte Constitucional deben ser interpretados como un cuestionamiento radical al uso de la orientación sexual como un criterio para determinar quiénes pueden acceder a la ciudadanía plena. Conforme con la Corte, en una democracia liberal como la colombiana el Estado debe tratar a todos sus ciudadanos con igual consideración y respeto. El Estado no puede hacer uso de los recursos a su disposición, el derecho y la fuerza pública, por ejemplo, para promover los proyectos de buen vivir de algunos de sus ciudadanos.

La vida en pareja constituye una de las formas mediante las cuales los seres humanos intentan materializar sus proyectos de buen vivir. Es un medio a través del cual buscan concretar sus compromisos morales. Permitir que el sistema jurídico desconozca su existencia no sólo envía a la sociedad un mensaje en donde se califica negativamente a las orientaciones sexuales no tradicionales, asunto que no es competencia del Estado, sino que también les impone unos costos muy altos a quienes las encarnan, por ejemplo, marginación social y gastos económicos relacionados con el manejo y liquidación del patrimonio común. Sin embargo, el costo más alto que tienen que pagar los miembros de las parejas del mismo sexo está relacionado con el hecho de que el sistema jurídico les niega su plena humanidad. Para el sistema jurídico, estas personas no son miembros completos del género humano; su autonomía y racionalidad son restringidas radicalmente en tanto que el resultado de su ejercicio es calificado negativamente por el Estado.

El segundo argumento tiene que ver con el giro radical que le da la Corte Constitucional a su jurisprudencia. Hasta la sentencia C-075 de 2007, el Tribunal no había reconocido a los miembros de las parejas del mismo sexo como sujetos de derecho, aunque había protegido los derechos de personas con orientaciones sexuales no tradicionales en su condición de individuos ${ }^{38}$. Entre 1991 y 2007, la Corte señaló que las instituciones de formación de la fuerza pública no pueden expulsar a sus miembros por el solo hecho de que éstos sean homosexuales; que los colegios públicos y privados no pueden expulsar a los estudiantes homosexuales porque consideren que su orientación sexual es inmoral y que la homosexualidad no es una falta al honor militar o a los deberes que tienen los docentes de los colegios públicos ${ }^{39}$. Sin embargo, durante este mismo periodo la Corte señaló que el Estado está facultado constitucionalmente para prohibir que las parejas del mismo sexo adopten niños, que es constitucional que en Colombia un homosexual no pueda afiliar al sistema de seguridad social a su pareja y que la Constitución acepta que la ley que regula la unión marital de hecho sea aplicable únicamente a las parejas heterosexuales ${ }^{40}$.

38 Ver, LEMAITRE, Julieta. Los derechos de los homosexuales y la Corte Constitucional: (casi) una narrativa de progreso. En: BONILLA, Daniel y MANUEL, Iturralde (eds). Hacia un nuevo derecho constitucional. Bogotá, Colombia. Universidad de los Andes, 2005, pp. 181-217.

39 En las sentencias T-097 de 1994 M.P. Eduardo Cifuentes Muñoz, T-101de 1998 M.P. Fabio Morón Díaz, C-481 de 1998 M.P. Alejandro Martínez Caballero, C-507de 1999 M.P. Vladimiro Naranjo Mesa, T-618 de 2000 M.P. Alejandro Martínez Caballero, se concede el amparo de los derechos fundamentales a los individuos homosexuales.

40 En las sentencias C-098 de 1996 M.P. Eduardo Cifuentes Muñoz (unión marital de hecho), T-618 de 2000 (afiliación al sistema de seguridad social), T-999 de 2000 M.P. Fabio Morón Díaz (afiliación al sistema de seguridad social), T-1426 de 2000 M.P. Álvaro Tafur Galvis (afiliación al sistema de Seguro Social), SU-623 de 2001 M.P. Rodrigo Escobar Gil (afiliación al sistema de seguridad social)I, C-814 de 2001M.P. Marco Gerardo Monroy Cabra (adopción); T-725 de 2004 (derecho a residencia de la pareja del mismo sexo en la isla de San Andrés); y T-349 de 2006 (sustitución pensional), no se reconocen los derechos de las parejas homosexuales. 
Con la expedición de la sentencia C-075 de 2007, la Corte reconoce que el ámbito de discrecionalidad que tiene el legislador para regular las prácticas sociales no es ilimitado en materias relacionadas con la orientación sexual. El argumento central que había servido para declarar la constitucionalidad de las normas que regulaban cuestiones relacionadas con las parejas heterosexuales, pero omitían cualquier referencia a las parejas del mismo sexo, acepta ahora la Corte, no tiene fundamento cuando están en juego principios constitucionales estructurales, como la dignidad, y derechos fundamentales de los ciudadanos como la igualdad y el libre desarrollo de la personalidad. El legislador no puede dejar de regular cuestiones relacionadas con las parejas del mismo sexo cuando crea normas que regulan las parejas heterosexuales dado que, en principio, por lo menos en cuestiones patrimoniales no hay diferencia entre una y otra forma de asociación. De este modo, la libertad del legislador tiene fronteras negativas y positivas. El legislador no debe, en principio, regular cuestiones relacionadas con la orientación sexual de los ciudadanos. No obstante, cuando tenga la potestad, debe hacerlo de manera coherente con la protección de los derechos y principios básicos de un Estado Social de Derecho y no puede dejar de incluir los casos análogos a los que pretende regular en primera instancia.

Ahora bien, es importante recordar que los cambios articulados por la Corte Constitucional son formales, esto es, meras transformaciones en el ordenamiento jurídico. El avance en el reconocimiento de la igual dignidad de los seres humanos es un avance jurídico que apenas acerca a la comunidad política colombiana a los ideales de la revolución francesa. En materia de orientación sexual estamos hasta ahora aproximándonos al siglo XVIII. La discriminación social y la violencia en contra de la comunidad LGBT sigue siendo un hecho evidente en Colombia ${ }^{41}$.

No obstante, este reconocimiento jurídico tiene valor simbólico y material. Por un lado, la comunidad política por primera vez reconoce las estrechas conexiones que existen entre la igual dignidad de todos sus ciudadanos y su orientación sexual. El discurso político-jurídico cambió con este conjunto de sentencias y, consecuentemente, las reglas del juego dentro de la polis se transformaron. De este modo, la imaginación jurídico-política se amplía y se reduce a la vez. El conjunto de titulares de la ciudadanía plena incluyen ahora a los miembros de la comunidad LGBT y no es posible ya excluir de la polis a las personas que no se reconocen como heterosexuales. Además, no hay que perder de vista el poder que tiene el derecho para cambiar los imaginarios sociales. El derecho, con la carga emotiva positiva con la que generalmente se le asocia y el aparato coercitivo que tiene a su servicio, está ahora del mismo lado de la diversidad sexual. A largo plazo, este hecho, adecuadamente utilizado, puede contribuir a cambiar las prácticas sociales que discriminan a las minorías sexuales.

Por el otro lado, esta transformación jurídica confirió a los ciudadanos herramientas poderosas para oponerse a las acciones estatales y del sector privado que violan el derecho que tienen los colombianos a vivir de acuerdo con su orientación sexual. Los miembros de las parejas del mismo sexo tienen hoy a su servicio los instrumentos que el sistema jurídico le otorga a las personas para defender sus derechos fundamentales, en particular, la acción de tutela, las acciones civiles que permiten compensar los daños causados a las víctimas y las acciones penales (que permiten sancionar a quienes se nieguen a cumplir con los mandatos constitucionales).

En tercera instancia, este conjunto de sentencias evidencian el cambio que se ha dado en la última década en la manera como la sociedad colombiana percibe a las minorías sexuales. La Corte Constitucional es una institución compuesta por nueve magistrados, muchos de los cuales defienden posiciones conservadoras en materias sociales -perspectivas que la mayoría de las

41 Derechos Humanos de lesbianas, gays, bisexuales y transgeneristas en Colombia 2006-2007, disponible en: http://www. colombiadiversa.org/index.php?option=com_content\&task=view\&id=563\&ltemid=370 
veces están influenciadas por la doctrina de la Iglesia Católica. Es diciente, por consiguiente, que este conjunto de sentencias haya sido aprobado por consenso o por amplias mayorías dentro del Tribunal Constitucional. La sentencia hito, aquella que abrió la línea jurisprudencial, fue aprobada por ocho magistrados. La única disidencia, que se concretó en el salvamento de voto del magistrado Araujo, se generó porque la sentencia no había ido lo suficientemente lejos en la protección de los derechos de los miembros de las parejas del mismo sexo. En la práctica, entonces, hubo un consenso dentro de la Corte en torno a la idea de que la Constitución de 1991 exige que se reconozca a las parejas del mismo sexo ${ }^{42}$.

De igual forma, el hecho de que buena parte de la comunidad política apoyó o no se opuso a los fallos promulgados por la Corte Constitucional, evidencia que el país ha dado algunos pasos hacia el reconocimiento de la diversidad sexual. Este hecho se hizo explícito en el amplio y positivo cubrimiento que tuvieron los casos en los medios de comunicación ${ }^{43}$, y en el hecho de que buena parte de la jerarquía católica aceptó estas transformaciones jurídicas en tanto tenían que ver con cuestiones civiles, particularmente asuntos patrimoniales, relacionadas con la vida en pareja ${ }^{44}$. Estos temas, argumentaron muchos de los jerarcas católicos, son de competencia del Estado, no de la Iglesia ${ }^{45}$. La narrativa con la que se describen a las minorías sexuales, por tanto, ha venido

42 Una situación muy similar se presentó en los otros seis casos decididos por la Corte Constitucional. Igualmente, la votación en la sentencia C-811/2007 fue de siete votos a favor y dos en contra. Los salvamentos de voto fueron de los magistrados Araujo y Pinilla, aunque el magistrado Araujo, nuevamente, se opuso al fallo por no ser suficientemente amplio en la protección de los derechos de la comunidad LGBT. En la sentencia C-336/2008 la votación fue de seis votos a favor y dos en contra. El magistrado Cepeda estuvo ausente de la sala plena en la que se decidió el caso y los magistrados Araujo y Pinilla, de nuevo, salvaron su voto y reiteraron los argumentos, muy distintos, que expusieron en las sentencias anteriores. En la sentencia C-798 de 2008, la decisión fue de siete votos a favor y dos en contra -con los magistrados Pinilla y Escobar en la minoría; y en la sentencia C-029/2009, la votación fue de ocho votos a favor y uno en contra (salvamento de voto parcial del magistrado Pinilla). Finalmente, en las sentencias T-856/ 2007 y T-1241/200, que en tanto casos de revisión de tutela se deciden por paneles compuestos por tres magistrados, las votaciones fueron 3-0, es decir, hubo unanimidad en el panel en torno a que la línea jurisprudencial establecida por la Corte Constitucional sobre la materia era aplicable a los casos bajo estudio. De esta forma solo ha habido un miembro de la Corte que de manera recurrente se ha manifestado en contra del reconocimiento de algunos derechos para los miembros de las parejas del mismo sexo, el magistrado Nilson Pinilla (el magistrado Escobar solo fue disidente en uno de los siete casos decididos por la Corte Constitucional relacionados con el reconocimiento jurídico de las parejas del mismo sexo).

43 Ver, por ejemplo, Diario El Universo. "Colombia legitima el vínculo entre los gays" http://www.eluniverso.com/200 7/02/09/0001/14/70DBA374EAE0492DA8D2D463B9C70EA0.aspx; Revista Semana. "Corte Constitucional reconoce derechos patrimoniales a parejas 'gay'” http://www.semana.com/wf_InfoArticulo.aspx?idArt=100889; RCN Radio. "Fallo sobre derechos patrimoniales de parejas homosexuales genera controversia" http://www.rcn.com.co/noticia. php3?nt=17978; Periódico El Tiempo. "Sentencia de la Corte sobre derechos patrimoniales de parejas homosexuales es explicada por Rodrigo Escobar Gil (La W)" http://www.eltiempo.com/multimedia/audio/actualidad/AUDIO-WEBPLANTILLA_AUDIOS-3430967.html?id_recurso=3430967\&id_articulo=3430779; Caracol Radio. “¿Cuáles son los alcances del fallo de la Corte, que garantiza los derechos patrimoniales de las parejas del mismo sexo?" http://caracol. com.co/noticias/388790.asp; Periódico El Colombiano. "Parejas homosexuales ganan sus derechos patrimoniales" http://www.elcolombiano.com.co/BancoConocimiento/P/parejas_homosexuales_ganan_sus_derechos_patrimoniales/ parejas_homosexuales_ganan_sus_derechos_patrimoniales.asp

44 No obstante, la jerarquía católica se opuso firmemente a que se reconociera el derecho al matrimonio o la adopción de los miembros de las parejas del mismo sexo.

45 La agencia de noticias católica ACIPRENSA -lo que todo católico necesita saber, reportó al respecto: "A finales de septiembre, el Presidente de la Conferencia Episcopal de Colombia, Mons. Luis Augusto Castro, expresó que aunque la Iglesia no tiene nada que decir 'en contra del patrimonio y la seguridad social de los homosexuales', estos objetivos se pueden alcanzar sin necesidad de 'introducir una figura de matrimonio camuflado y sin dar un golpe más duro a la estructura familia'. En: http://www.aciprensa.com/noticia.php?n=14432 La cadena Caracol reportó en el mismo sentido lo siguiente, "El secretario general de la Conferencia Episcopal Colombiana, monseñor Fabián Marulanda, señaló que dentro de los principios de respeto y no discriminación hacia los homosexuales, 'está bien que se garanticen los derechos patrimoniales de las uniones homosexuales'. El prelado señaló que lo importante para la Iglesia Católica es que las parejas del mismo sexo no alcancen el mismo nivel del matrimonio de las parejas heterosexuales, y agregó que el clero tampoco aceptaría que se les otorgara a las uniones 'gay', el derecho de adopción". http://www.caracol.com. co/nota.aspx?id=388585 
cambiando en Colombia. De un discurso centrado en el pecado o en la enfermedad se van dando pasos importantes hacia uno centrado en el reconocimiento a la diferencia sexual ${ }^{46}$.

Finalmente, la jurisprudencia de la Corte Constitucional contribuye a reflexionar en torno al reconocimiento de la diferencia sexual de una manera novedosa cuando hace uso del principio de dignidad humana. Cuando el Tribunal apela a este principio para justificar sus decisiones, ofrece algunas herramientas conceptuales que permiten comprender y evaluar de manera rica, compleja y fresca los problemas que genera para una democracia liberal el no reconocimiento jurídico de las parejas del mismo sexo. Sin embargo, en tanto que la Corte también se apoya en los derechos a la igualdad y el libre desarrollo de la personalidad para fundamentar sus fallos, su argumentación genera algunas importantes tensiones teóricas.

\section{Los modelos de la autonomía, la igualdad y la dignidad}

El reconocimiento jurídico de las parejas del mismo sexo puede comprenderse y fundamentarse apelando a tres modelos distintos: autonomía, igualdad y dignidad. Ahora bien, aunque la igualdad y dignidad ofrecen herramientas conceptuales y prácticas complementarias, el modelo de la autonomía resulta incompatible con las otras dos estructuras normativas. El modelo de la dignidad y el de la igualdad interpretan el problema que es objeto de estudio de manera distinta y generan consecuencias sustanciales y procedimentales para la comunidad política que son inconciliables con el modelo de la autonomía ${ }^{47}$. Es importante precisar que cada uno de estos modelos recoge como su eje central a uno de los derechos a los que apela la Corte Constitucional para justificar su línea jurisprudencial. De igual forma, es necesario señalar que los tres modelos coexisten, en tensión, dentro de cada una de las sentencias promulgadas por la Corte sobre el reconocimiento jurídico y derechos de las parejas del mismo sexo. Finalmente, los modelos no aparecen de manera completa en las sentencias de la Corte Constitucional colombiana; solo sus elementos estructurales lo hacen. Esta sección del artículo, por tanto, busca precisar y desarrollar los contenidos de estos elementos, explicitar sus fundamentos y analizar sus consecuencias teóricas y prácticas.

El modelo de la autonomía argumenta que las cuestiones relacionadas con la vida sexual y afectiva incumben únicamente a los individuos involucrados. El Estado no tiene competencia alguna para involucrarse en asuntos que tienen que ver con los proyectos de buen vivir de sus ciudadanos. Las personas, argumenta el modelo de la autonomía, tienen el derecho a "ser dejadas solas" 48 ; tienen el derecho a que el Estado no invada el espacio íntimo donde articulan, modifican e intentan volver realidad sus compromisos morales ${ }^{49}$. En términos de la Corte Constitucional colombiana,

"...el derecho al libre desarrollo de la personalidad consagra una protección general de la capacidad que la Constitución reconoce a las personas para autodeterminarse, esto es, a darse sus propias

46 No hay que olvidar que la sodomía fue un delito en Colombia hasta 1980 y que la Asociación Estadounidense de Psiquiatría, referente fundamental para la psiquiatría colombiana, sólo hasta 1973 eliminó a la homosexualidad de su listado de enfermedades mentales.

47 BURT, Robert. Regulando la sexualidad: Libertad frente a Igualdad. SELA, 2009, p. 2, disponible en http://www.law. yale.edu/intellectuallife/sela2009.htm. En este texto, Burt argumenta que el modelo de la igualdad y el de la autonomía son irreconciliables.

48 WARREN, Samuel y BRANDEIS, Louis. The Right to privacy. Harvard Law Review (4): 193-220, 1890.

49 Este es un modelo que se ha utilizado para justificar tanto el reconocimiento de las parejas del mismo sexo como otros derechos relacionados con la sexualidad. Es, como se ha visto, uno de los argumentos que fundamenta la línea jurisprudencial de la Corte Constitucional colombiana que reconoce la existencia jurídica de las parejas del mismo sexo. Sin embargo, también ha sido un modelo utilizado en el contexto anglosajón para justifica fallos de la Corte Suprema de Justicia tan importantes como Roe v. Wade (aborto), Griswold v. Connecticut (derecho de la parejas casadas a usar anticonceptivos), y Lawrence v. Texas (junto al argumento de la igualdad permitió que se declararan inconstitucionales las normas que sancionaban las relaciones sexuales entre parejas del mismo sexo). 
normas y desarrollar planes propios de vida, siempre y cuando no se afecten derechos de terceros o el orden jurídico. Para la Corte este derecho se vulnera 'cuando a la persona se le impide, en forma irrazonable, alcanzar o perseguir aspiraciones legítimas de su vida o valorar y escoger libremente las opciones y circunstancias que le dan sentido a su existencia y permiten su realización como ser humano'" 150 .

Este modelo se entrecruza con el argumento del liberalismo que defiende la separación entre la órbita de lo privado y la de lo público ${ }^{51}$. El ámbito de lo privado, argumentan los liberales, es el ámbito de la moral, el espacio donde el individuo construye su proyecto de buen vivir. El ámbito de lo público es el ámbito de la justicia, el espacio donde se construye la estructura básica de la comunidad política; la esfera donde se distribuye el poder político y los recursos escasos que controla la sociedad. La frontera que divide estas dos esferas tiene como objetivo precisar firmemente los límites que configuran el espacio de acción legítima del Estado, esto es, precisar los contornos que fijan el espacio de lo político. El Estado, por consiguiente, no puede cruzar la frontera que divide estas dos esferas sin violar dos de los principios básicos del liberalismo: aquel que indica que el Estado debe tratar con igual consideración y respeto a todos los asociados y aquel que señala que cada individuo tiene derecho a construir y materializar su proyecto moral sin intervención alguna del Estado ${ }^{52}$.

Ahora bien, este modelo tiene debilidades importantes. En primera instancia, es una perspectiva radicalmente individualista que entiende a los seres humanos como mónadas sin conexiones relevantes con la comunidad ${ }^{53}$. El modelo de la autonomía parte del supuesto de un sujeto fuerte que construye (y debe construir) su identidad de manera solitaria. La satisfacción de esta necesidad, para el modelo de la autonomía, se garantiza jurídica y políticamente a través del derecho a ser libre, es decir, el derecho que tienen las personas a ser dejadas solas ${ }^{54}$. De esta forma, el modelo de la autonomía ve con desconfianza las relaciones humanas ${ }^{55}$, pues constituyen obstáculos para la construcción libre del sujeto.

El modelo pierde de vista que la autonomía no se ejerce en abstracto sino en contextos que limitan, pero al mismo tiempo constituyen al individuo. Los horizontes de perspectivas en los que los sujetos están ineludiblemente inmersos prescriben cuáles son las opciones vitales disponibles para el sujeto, así como el valor moral que cada una de ellas tiene ${ }^{56}$. La autonomía, por tanto, se ejerce dentro de las fronteras establecidas previamente por este entramado de interpretaciones de la realidad ${ }^{57}$. El sujeto no dispone de una cantidad infinita de posibilidades de ser en el mundo para construir su identidad individual, sino solo de las alternativas que existen dentro de la comunidad a la que pertenece.

El modelo de la autonomía oscurece la dimensión comunitaria que tiene el género, y, por tanto, la dimensión política que tiene el problema del no reconocimiento jurídico de las parejas del

50 Sentencia C-075/2007 (itálica en el original).

51 DWORKIN, Ronald. Ética privada e igualitarismo político. Barcelona, Paidós, 1993, pp. 49-66.

52 DWORKIN, Ronald. Liberalism, en Ethische und politische Freiheit. NIDA-RÜMELIN, Julian y VOSSENKUHL, Wilhelm (eds.). New York-Berlín, Walter de Gruyter, 1998, pp. 180-204.

53 WILLIAMS, Patricia. On being the object of property. En: Feminist Legal Theory: Readings in Law and Gender, ed., BARTLETT, Katherine y KENNEDY, Rosanne. Westview Press, 1991, pp. 165-80.

54 ALLEN, Anita. Privacy. En: JAGGAR, Alisson M. y YOUNG, Iris Marion (eds). A Companion to Feminist Philosophy, Blackwell, 2000.

55 WEST R., Forward: taking freedom seriously. Harvard Law Review (55): pp. 1-72, 1988.

56 TAYLOR, Charles. Ética de la autenticidad. Paidós, 1994, pp. 67-76.

57 KYMLICKA, Will. Ciudadanía multicultural. Paidós, 1996, pp. 120-122. 
mismo sexo ${ }^{58}$. Escoger entre los roles disponibles para cada género, violentarlos y ser cuestionado, o materializarlos y ser reconocido, por ejemplo, solo tiene sentido socialmente ${ }^{59}$. Los individuos -mónadas, si existieran- no tendrían mayores problemas con el rompimiento de los roles asignados socialmente al género al que supuestamente pertenecen, pues la construcción de su identidad individual no depende de forma alguna de la mirada que "el otro" tiene de nosotros y que constantemente nos proyecta. Estos sujetos olvidan que la vida en pareja es a la vez una cuestión privada y pública: compete de manera directa y especial a los individuos, pero éstos la entienden en buena parte a través de los lentes interpretativos que la comunidad provee. El reconocimiento jurídico de las parejas del mismo sexo, entonces, tiene como objetivo que la comunidad política declare formalmente que ser parte de una pareja del mismo sexo es tan valioso, genéricamente, como de una pareja de heterosexuales. No reconocerlas jurídicamente implica someter a los miembros de las parejas del mismo sexo a una estructura oficial de subordinación que los condena a una posición de inferioridad moral frente a los individuos de parejas heterosexuales.

En segunda instancia, el modelo de la autonomía pierde de vista la violación del derecho de igualdad y el principio de dignidad humana que genera el no reconocimiento de las parejas del mismo sexo. En relación con la igualdad, el modelo de la autonomía es incapaz de ver que parte del problema radica en que las parejas del mismo sexo son tratadas de manera distinta a como son tratadas las parejas heterosexuales. La cuestión no es sólo que los individuos tengan la posibilidad de compartir su vida con quienes así lo decidan, asunto que el modelo de la autonomía recoge y protege, sino en las consecuencias jurídicas y políticas que genera la distinción injustificada entre parejas del mismo sexo y las heterosexuales. El modelo de la autonomía, por tanto, oscurece el problema de igualdad que atraviesa la jurisprudencia de la Corte Constitucional colombiana sobre las parejas del mismo sexo. Para la Corte,

"Las mismas consideraciones que permiten establecer que en relación con la situación patrimonial de las parejas homosexuales existe un déficit de protección a la luz del ordenamiento constitucional, Ilevan a la conclusión de que el régimen de la Ley 54 de 1990[...] en la medida en que se aplica exclusivamente a las parejas heterosexuales y excluye de su ámbito a las parejas homosexuales, resulta discriminatorio. Así, no obstante las diferencias objetivas que existen entre los dos tipos de pareja, y las específicas consideraciones que llevaron al legislador del año 1990 a establecer este régimen de protección, fundadas en la necesidad de proteger a la mujer y a la familia, no es menos cierto que hoy por hoy puede advertirse que las parejas homosexuales presentan requerimientos análogos de protección y que no existen razones objetivas que justifiquen un tratamiento diferenciado"60.

La marginación del derecho de igualdad de la manera como se comprende y evalúa el no reconocimiento jurídico de las parejas del mismo sexo genera dos problemas que están estrechamente entrelazados: uno de igualdad tenue y otro de igualdad fuerte. El problema de igualdad tenue tiene que ver con el hecho de que dos casos análogos son tratados de manera diferente, pues no parece haber diferencias fundamentales que justifiquen un trato diferenciado por parte del sistema jurídico. Tanto las parejas del mismo sexo como las heterosexuales son formas de asociación que tienen como objetivo permitir que dos personas compartan su vida afectiva, sexual y financiera.

El problema de igualdad fuerte es que el hecho de que parejas heterosexuales sean reconocidas jurídicamente y las parejas del mismo sexo no lo sean, tiene como justificación una diferenciación

\footnotetext{
58 BURT, Robert. Regulando la sexualidad: Libertad frente a Igualdad, op. cit., p. 17.

59 Ibid.

60 C-075/2007.
} 
más profunda entre los miembros que componen uno y otro tipo de asociación. Los primeros son reconocidos como miembros plenos del género humano mientras que los segundos son excluidos del mismo ${ }^{61}$. El modelo de la autonomía es incapaz de comprender que el núcleo del problema que produce el silencio jurídico frente a las parejas del mismo sexo está relacionado con el no reconocimiento de los miembros de este tipo de parejas como miembros plenos del género humano. Desconoce que las relaciones de pareja constituyen elementos centrales para desarrollarse como seres humanos. Este hecho se hace más evidente cuando las razones para la exclusión de las parejas del mismo sexo del ordenamiento jurídico son de corte religioso y apuntan a indicar que las relaciones sexuales y afectivas entre individuos del mismo sexo son contra natura.

El modelo de la autonomía concentra toda la atención en la decisión que toman los individuos de hacer parte de una pareja del mismo sexo y no en el contenido de la decisión ${ }^{62}$ y en las consecuencias simbólicas y materiales que éste genera. El modelo se limita a defender que la decisión de conformar una pareja debe ser respetada por el Estado en tanto que fue una decisión tomada por dos adultos capaces. La materia de la decisión le resulta irrelevante. No exige, por tanto, que el Estado actúe para reconocer la existencia de las parejas del mismo sexo sino que reclama que el Estado se abstenga de actuar frente a cualquier tema que tenga que ver con la vida sexual y afectiva de las personas y, consecuentemente, pierde de vista que el Estado ya se puso en movimiento de manera injustificada para reconocer únicamente la existencia jurídica de las parejas heterosexuales.

En relación con el principio de dignidad humana, el modelo de la autonomía es incapaz de evidenciar que tras el problema de igualdad tenue que surge como consecuencia del no reconocimiento jurídico de las parejas del mismo sexo subyace un problema de desconocimiento de las características del ser humano que el liberalismo califica como constitutivas de todos los miembros de la especie: su autonomía y racionalidad ${ }^{63}$. Como se analizará en detalle en los próximos apartes, el modelo de la igualdad (así como el de la autonomía) no describe de manera precisa y completa el problema: la cuestión no es que seamos dignos porque somos iguales, sino que somos iguales porque somos dignos. El no reconocimiento jurídico de las parejas del mismo sexo viola la igualdad en un sentido fuerte porque viola la dignidad humana, no viceversa.

El modelo de la igualdad ofrece una interpretación distinta a la que articula el modelo de la autonomía sobre los problemas teóricos y prácticos que genera el no reconocimiento jurídico de las parejas del mismo sexo. Para esta perspectiva, como se evidenció arriba, el problema central es la violación del derecho a la igualdad en un sentido tenue y en un sentido fuerte. La igualdad en un sentido tenue se viola cuando se utiliza injustificadamente la orientación sexual de los ciudadanos como criterio para distribuir derechos y obligaciones básicos entre los ciudadanos. La igualdad en un sentido fuerte se transgrede cuando se distingue infundadamente entre dos grupos de sujetos, los miembros de las parejas del mismo sexo y los de parejas heterosexuales, para negarle a los primeros su calidad de seres humanos. La jurisprudencia de la Corte Constitucional colombiana sobre parejas del mismo sexo se concentra en el problema de igualdad tenue. La argumentación del tribunal, cuando hace referencia al derecho de igualdad, se concentra en denunciar el carácter injustificado de la distinción que hace el ordenamiento jurídico entre parejas del mismo sexo y parejas heterosexuales. El problema de igualdad fuerte no aparece explícitamente en la

61 Burt, Robert, Ibid., pp. 14 y 17.

62 Ibid., p. 11.

63 WALDRON, Jeremy. The Theoretical Foundations of Liberalism. En: NIDA-RÜMELIN, Julian y VOSSENKUHL, Wilhelm (eds.). Ethische und politische Freiheit. New York-Berlín, Walter de Gruyter, 1998, p. 227. 
jurisprudencia de la Corte. Más bien, aparece implícitamente y como un problema directamente relacionado con el principio de dignidad humana ${ }^{64}$.

El modelo de la igualdad tiene la virtud de explicitar la dimensión política que tiene la orientación sexual, el carácter dialógico de la construcción de la identidad individual y el papel que juega el derecho en este proceso. El entramado de posibilidades que ofrece la comunidad en la que se está inmerso condiciona y carga de sentido las decisiones que los individuos toman en torno a su vida sexual y afectiva. Este modelo también evidencia las conexiones que existen entre el principio de igual ciudadanía y el principio que afirma la igualdad básica de todos los seres humanos, y exige que el Estado haga lo necesario para proteger el derecho a la igualdad del que son titulares los miembros de las parejas del mismo sexo.

No obstante, el modelo de la igualdad, tanto como el modelo de la intimidad, es incapaz de dar cabal cuenta del problema central que genera el no reconocimiento de las parejas del mismo sexo. Este modelo pierde de vista que la igualdad en sentido tenue depende de la igualdad en sentido fuerte y que ésta, a su vez, es un derecho que depende del principio de dignidad humana. Si como se argumenta desde el modelo de la igualdad, lo que está realmente en juego no es si los criterios para distinguir entre miembros de las parejas del mismo sexo son o no plausibles sino la pertenencia misma al género humano. Como se mencionó antes, los seres humanos no somos dignos porque somos iguales sino que somos iguales porque somos dignos. El hecho de que se considere que la autonomía y la racionalidad son características centrales de los seres humanos y que se tenga la convicción de que todos los seres humanos nacen con esas capacidades es lo que posibilita que se pueda calificar a todos los miembros de la especie como fundamentalmente iguales.

De igual modo, el modelo de la igualdad oscurece el hecho de que el no reconocimiento jurídico de las parejas del mismo sexo violenta también la autonomía de sus miembros. La cuestión no es, como se articula desde el modelo de la autonomía, que el Estado debe abstenerse de actuar en materias relacionadas con la vida sexual y afectiva de las personas. El asunto es que debe hacerlo, reconociendo jurídicamente a las parejas del mismo sexo, de manera que las personas puedan efectivamente ejercer su autonomía. La omisión del Estado en esta materia envía un doble mensaje: las orientaciones sexuales alternativas son cuestionables moralmente y quien escoja vivir conforme a ellas tendrá que pagar notables costos (económicos, sociales, políticos) que las personas heterosexuales no tienen que pagar.

El tercer modelo, en contraste, gira en torno al principio de la dignidad humana. Este principio señala, como se ha dicho antes, que todos los seres humanos somos dignos en tanto que tenemos la capacidad de articular, modificar y materializar, haciendo uso de la razón, proyectos de buen vivir y de justicia. Es decir que, como lo señala continuamente la jurisprudencia de la Corte Constitucional colombiana sobre parejas del mismo sexo ${ }^{65}$, los miembros de la especie humana somos iguales en tanto que somos fundamentalmente seres autónomos y racionales. Estas capacidades comunes son violadas, argumenta el modelo de la dignidad, cuando el ordenamiento jurídico no reconoce a las parejas del mismo sexo. Los proyectos de buen vivir de la mayoría de las personas incluyen una dimensión de vida en pareja que se niega de manera radical para

64 Para la Corte en la sentencia C-075/2007, “...La afectación de la dignidad, finalmente, también se desprende de una manera directa, de la ausencia de reconocimiento jurídico de las opciones vitales de las personas. Ello se produce en este caso porque la realidad de las parejas homosexuales y de las personas que las integran no es reconocida y resulta invisible para el ordenamiento jurídico, puesto que, no obstante que dichas personas han obrado en ejercicio de una opción protegida por la Constitución, son ignoradas por el ordenamiento jurídico cuando se trata de resolver los conflictos patrimoniales que pueden surgir de tal decisión".

65 Ver notas al pie 24 y 25. 
los individuos con orientaciones sexuales alternativas cuando no se reconocen las parejas del mismo sexo. El Estado, con su omisión, está evitando que las personas tomen autónomamente una decisión sobre el tipo de vida que quieren vivir que no afecta negativamente los derechos de terceras personas. Está limitando de manera radical e injustificada la potestad misma de escoger libremente un proyecto de vida. El Estado, con su inacción, está indicando que prefiere una orientación sexual -la heterosexual-por sobre otra -la homosexual-y, que, por tanto, los individuos deberían escoger la primera y no la segunda.

La cuestión no es sólo que las personas puedan vivir con la pareja de su elección sin que el Estado las sancione, sino que éste reconozca la vida de las parejas del mismo sexo como una alternativa válida para la comunidad política. Este reconocimiento tiene un valor simbólico poderoso, el reconocimiento de los miembros de las parejas del mismo sexo como seres humanos iguales a los heterosexuales; y un valor material, relacionado con la reducción de los costos patrimoniales de la vida en pareja y la disminución de la discriminación y la violencia en contra de la comunidad LGBT.

El modelo de la dignidad ofrece varias ventajas frente a los modelos con los que compite. En primera instancia es una estructura normativa comprehensiva. Incluye tanto una dimensión de igualdad como una de autonomía. El modelo no es producto de un eclecticismo débil que busca combinar el modelo de la igualdad con una reinterpretación del modelo de la autonomía. La igualdad y la autonomía se aparejan estructuralmente en el concepto de dignidad humana. De hecho, los derechos de igualdad (tenue) y del libre desarrollo de la personalidad son instrumentos que se derivan y sirven para la defensa de la dignidad. La igualdad, en el modelo de la dignidad, se entiende como igualdad básica (fuerte) de los seres humanos. Esta igualdad es una función de la autonomía y racionalidad de las que gozan todos los individuos. De hecho, la igualdad tenue, que hace parte del modelo de la igualdad, y que depende de la igualdad fuerte, es una concreción y desarrollo de esta última. Es un derecho que otorga las herramientas para evaluar cuándo es legítimo que los miembros de la comunidad política sean tratados de manera diferenciada y cuáles serían las razones que permitirían cuestionar o fundamentar tales distinciones.

La autonomía, en el modelo de la dignidad, se entiende como una facultad básica que tienen todos los seres humanos y que sólo puede ejercerse de manera efectiva si se cumplen dos requisitos: la satisfacción de algunas necesidades materiales básicas, como la de ingerir cierto número de calorías diariamente, y la existencia de un marco jurídico-político amplio y respetuoso de los diversos proyectos de buen vivir que son posibles dentro de la comunidad, de manera que los ciudadanos tengan la potestad real de escoger los que consideren más valiosos de entre ellos ${ }^{66}$. De esta forma, la dignidad incluye, en los términos de la Corte Constitucional colombiana, tres dimensiones que se entrecruzan: el derecho a vivir como se quiera, el derecho a vivir sin humillaciones y el derecho a un mínimo vital.

En segunda instancia, la vaguedad del principio de dignidad y la posibilidad de fundamentarlo desde diversas perspectivas lo convierte en un espacio discursivo privilegiado para alcanzar acuerdos amplios dentro de una comunidad política plural ${ }^{67}$. El alto grado de generalidad del principio podría interpretarse en contra de la defensa del mismo. El significado de la dignidad humana, se podría argumentar, depende del intérprete y, por tanto, está a merced de las relaciones de poder

\footnotetext{
66 Ver también, GRANT, Evadne. Dignity and Equality. Human Rights Law Review 7 (2): 299-329, 2007. En este artículo se exploran las conexiones entre la igualdad y la dignidad en la jurisprudencia alemana y surafricana.

67 SIEGEL, Reva B. Dignity and the Politics of Protection: Abortion Restrictions Under Casey/Carhart. Yale Law Journal 117 : p. 101, 2008; y SIEGEL, Reva B. La dignidad y el debate del aborto. SELA, Junio 2009, p. 10 http://www.law.yale.edu/ intellectuallife/sela2009.htm
} 
que existen dentro de la comunidad política. Sin embargo, ésta parece ser una característica típica de todos los principios -no solo del de dignidad humana. Además, la vaguedad de los principios no es perpetua. A medida que son interpretados, particularmente por operadores jurídico-políticos con autoridad, su contenido se va precisando. Este contenido se vuelve obligatorio y, por consiguiente, se convierte en una guía para la conducta de las personas. Del mismo modo, el reconocimiento de que el contenido preciso del principio tiene un carácter contingente permite su variación como consecuencia de las transformaciones que vive la comunidad política.

Igualmente, dado que el principio puede llenarse de contenido y fundamentarse apelando a distintos tipos de argumentos -morales y seculares, religiosos e históricos-, un número amplio de personas puede aceptar que es un principio que vale la pena defender y entrar en procesos deliberativos que tengan como objetivo precisar su contenido. Así, personas que creen que el principio de dignidad humana debería salvaguardarse porque es una consecuencia de que los seres humanos hayan sido creados a imagen y semejanza de la divinidad ${ }^{68}$ o quienes creen que la autonomía y racionalidad son características esenciales de los seres humanos ${ }^{69}$ y quienes consideran que este es un principio construido históricamente para defender bienes que nos parecen valiosos, pueden estar de acuerdo en que la dignidad es uno de los ejes en torno a los cuales debe estructurarse una comunidad política ${ }^{70}$.

En tercera instancia, el modelo de la dignidad explica de manera clara, precisa y sencilla el problema que está en juego y lo interpreta y resuelve de manera que entronque con una interpretación iluminadora de la tradición política que sustenta el ordenamiento político-jurídico colombiano: el liberalismo.

Los modelos de la dignidad, la igualdad y la autonomía nos ofrecen una serie de herramientas conceptuales útiles para aproximarnos al problema del no reconocimiento jurídico de las parejas del mismo sexo, en particular, y de la discriminación por razones de orientación sexual, en general. Sin embargo, no podemos olvidar que el fin último no es interpretar más ricamente el problema, sino eliminarlo en la práctica. El asunto no es solo de claridad, precisión y sutileza jurídica y filosófica, sino de lucha política; de la construcción de una sociedad más igualitaria en donde la dignidad de todas las personas sea efectivamente protegida.

68 BOGNETTI, Giovanni. The Conception of Human Dignity in European and US Constitutionalism. En: NOLTE, Georg (ed.) European and Us Constitutionalism. 2005, p. 89. Ver también, LOERBAUM, Yair. Blood and the Image of God: On the Sanctity of Life in Biblical and Early Rabbinic Law, Myth and Ritual. En: KRETZMER, David y KLEIN, Eckart (eds.). The Concept of Human Dignity in Human Rights Discourse, 2002; RITSCHL, Dietrich. Can Ethical Maxins be Derived from Theological Concepts of Human Dignity. En: The Concept of Human Dignity in Human Rights Discourse, Loc. Cit, p. 87; CHANA, Safrai. Human Dignity in a Rabbinical Perspective. The Concept of Human Dignity in Human Rights Discourse, Loc. Cit.

69 Ver GEWIRTH, Alan. Human Dignity as the Basis of Rights. En: MEYER, Michael J. y PARENT, William A. (Eds.). The Constitution of Rights: Human Dignity and American Values. Ithaca, N.Y: Cornell University Press, 1992, pp. 99-109.

70 RAO, Neomi. On the Use and Abuse of Dignity. Constitutional Law. Columbia Journal of European Law. 14 (2): pp. $201-$ 256, 2008; George Mason Law \& Economics Research Paper No. 08-34. 